\title{
Environmental factors affecting the composition and diversity of the avian community in igune, a traditional agricultural landscape in northern Japan
}

Haruka Imai ${ }^{i^{*}}$, Tohru Nakashizuka ${ }^{1,2}$ and Michio Oguro ${ }^{1,3}$

\begin{abstract}
Background: "Igune," a traditional agricultural landscape in the Tohoku region of Japan, is characterized by small-scale artificial woodlots surrounding a farmer's house that are interspersed with paddy fields. During the rapid economic growth of Japan over recent decades, some igune woodlots have been abandoned or logged. Biodiversity conservation is an important issue worldwide, and traditional agricultural landscapes are of particular interest. To elucidate the role of igune landscapes in conserving biodiversity, we examined the effects of environmental factors on avian communities.

Results: The study was conducted in the suburban areas of Oshu and Hanamaki cities, Iwate Prefecture, Japan, at eight sites that varied in the density and area of igune woodlots within the landscape. Bird surveys were conducted from the middle to late breeding season, and several environmental factors of the igune landscape were also measured. The results of canonical correspondence analysis indicated that the characteristics of avian communities were mainly determined by the total forested area in the landscape. Increased total forested area and shrubs layer of igune woodlots did not cause a reduction in number of bird species of any habitat and foraging types, while increased both in species number and abundance of insectivores and forest species. The number of raptor species increased in igune sites without shrubs.
\end{abstract}

Conclusions: Our results suggest that maintaining igune landscapes may enhance avian diversity within this landscape, although the effects of shrubs within igune varied; developed bush communities increased the evenness of the avian community, whereas some raptor species preferred an open forest understory.

Keywords: Canonical correspondence analysis, Conservation, Igune, Japan

\section{Background}

"Igune," a traditional agricultural landscape unique to the Tohoku region of northeastern Japan, comprises of small-scale artificial woodlots (approximately 0.2 ha on average and 3 ha maximum) that surround farmers' houses and are interspersed with paddy fields (Fig. 1). The oldest woodlots were likely established more than 500 years ago (Fukuoka et al. 2002). Originally, igune served to protect houses from strong winds and snow in

\footnotetext{
* Correspondence: haruka.paru@gmail.com

'Graduate School of Life Sciences, Tohoku University Aoba, 6-3, Aramaki,

Aoba-ku, Sendai 980-8578, Japan

Full list of author information is available at the end of the article
}

the winter and to occasionally supply timber and provide a daily commodity for farmers (Hirabuki and Fukuda 2006). Igune was mostly composed of sugi (Cryptomeria japonica) trees because of the usefulness and commercial value of its timber. Several deciduous broadleaf tree species are also sometimes found in igune woodlots, which can account for up to approximately $50 \%$ of the all trees.

The cultural values of igune have recently gained increasing attention. For example, farmers utilize many non-timber products derived from igune for religious ceremonies and daily life, and these woodlots also contribute to the scenic beauty of Japanese traditional 


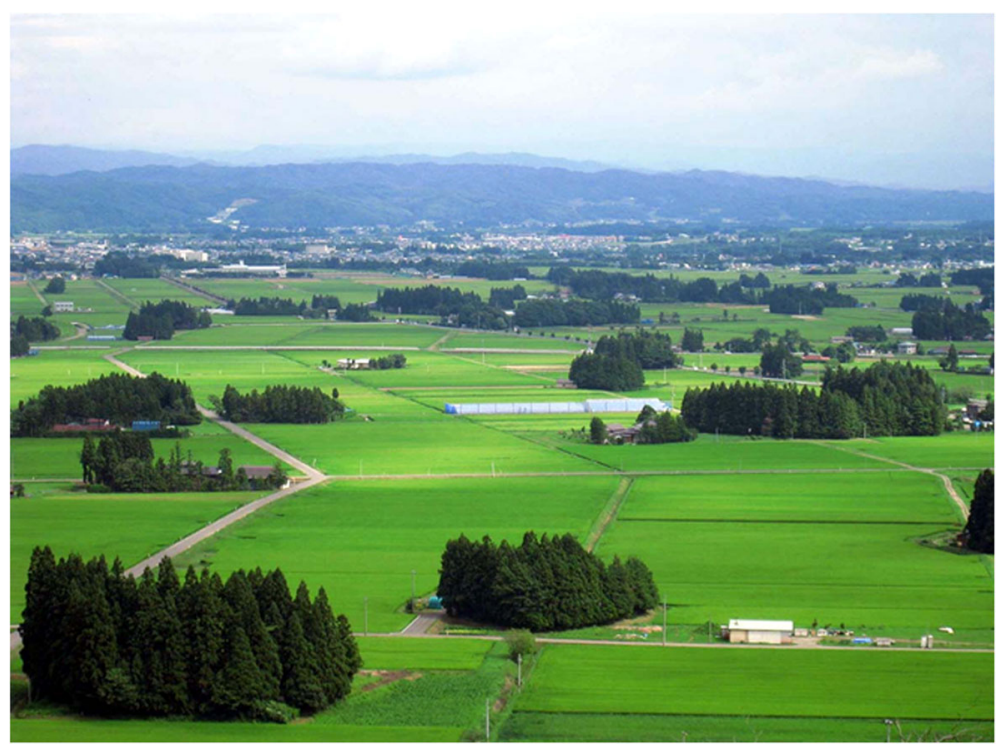

Fig. 1 The "igune" landscape. Farmers' houses are surrounded by woodlots. The picture was taken in Oshu City

landscapes (Ministry of Agriculture, Forestry and Fisheries of Japan 1991). During recent decades of strong economic growth in Japan, however, some igune woodlots have been abandoned or logged coincident with the shift from a traditional to modern lifestyle (Koganezawa et al. 2002; Hirabuki and Fukuda 2006). The lifestyle which utilizes igune is the best example of sustainable living and there are many points that we should learn from it. So, for this point, to conserve igune is very important.

Currently, biodiversity conservation has become an important issue worldwide. The Millennium Ecosystem Assessment, a program focusing on ecosystem changes and the future effects of these changes, demonstrated that biodiversity is crucial for various ecological services (Millennium Ecosystem Assessment 2005). Such conservation issues in human-dominated landscapes have been the subject of much research (Takeuchi 2003), and biodiversity in traditional agricultural landscapes such as igune is of particular interest in Japan (Hirabuki and Fukuda 2006). Especially, the small-scale artificial woodlots like igune are paid attention. Osawa and Katsuno (2001) suggested the importance of small-scale woodlots in paddy field as the habitat of Schlegel's green tree frog (Rhacophorus schlegelii) and Endo and Hirano (1990) reported that Japanese sparrowhawk (Accipiter gularis) often build a nest in small-scale woodlots surrounding a residence.

Murata and Takehara (unpublished observation) examined avian communities in igune and other landscapes in Oshu, Iwate Prefecture, and found that species richness was higher and species composition differed in igune compared to secondary forests. They concluded that the igune avian community included not only forest species but also open-land species, resulting in a richer avifauna.
Fukuoka et al. (2002) categorized the igune landscapes of Oshu into four groups based on plant species composition and management type. They reported that the dominance of dwarf bamboo and/or canopy closure led to the simplification of forest understory vegetation. Thus, the ecological factors affecting species richness and their significance in conserving the igune landscape warrant further research.

In this study, we focused on the avian community to examine the relationship between biodiversity and the igune landscape. Birds were selected as the target organism for several reasons: they are sensitive to habitat changes and thus good indicators of the ecosystem environment (Savard et al. 2000); birds are functionally diverse and interact with many other organisms such as plants and insects; they are relatively easy to observe and are ubiquitous among ecosystems and landscapes (Sandström et al. 2006); and birds are familiar to many people, and some species can serve as flagships for stimulating public interest in conservation (Simberloff 1998). Analyses of the ecological traits of bird species appear to be effective in linking diversity with the environment of avian habitats. In addition, some ecological traits, such as diet, are also considered functional groups in terms of ecosystem processes such as food-web interactions. Because the avian community usually includes several trophic levels within an ecosystem, analyzing the guild structure and functional groups of birds can estimate the stability of the focal ecosystem (Hino 2004; Gray et al. 2007).

To obtain baseline information for conserving avian diversity, we examined the igune traditional agricultural landscape with particular focus on the ecological factors of igune that affect avian communities. We hypothesized 
that igune provides secondary habitats for forest bird species. The igune landscape creates a forest-wetland (paddy) complex, generating spatially heterogeneous habitats within a monotonic paddy field landscape. The research sites were selected to vary in size and density of woodlots, and we attempted to elucidate the relationship between the extent of spatial heterogeneity of the forest-wetland complex and the diversity of the avian community. Subsequently, we analyzed the ecological traits of component species and examined the relationships between these characteristics and environmental factors. Finally, we evaluated this traditional agricultural landscape in terms of the conservation of avian diversity.

\section{Methods}

\section{Study site}

The study was conducted at eight sites within igune landscapes in the cities of Oshu and Hanamaki, Iwate Prefecture, Japan (Fig. 2). The sites varied in the size and density of igune woodlots as well as the distance from continuous forests.

Most of the farmland in the study area consists of paddy fields. Sugi was the most common tree species planted in igune woodlots, but occasionally, broadleaf trees such as chestnut (Castanea crenata) and elm (Zelkova serrata) were intermixed at varying densities. Historically, the shrubs in igune woodlots were clear-cut, although recently, some farmers have abandoned this management regime. The proportion of igune woodlots that experienced such shrub clearing varied among the study sites.

Each study site was a circle with a radius of $1 \mathrm{~km}$ (about $3.1 \mathrm{~km}^{2}$ in area). The sites included four groups of two sites each: $<60$ igune woodlots within the site (20 woodlots per $\mathrm{km}^{2}$ ), 60-80 igune woodlots per site, 80 100 woodlots per site, and $>100$ woodlots per site. One of the two sites in each group was located within $3 \mathrm{~km}$ of the nearest continuous forest (connected to high mountain areas), and the other site was more than $3 \mathrm{~km}$ from the nearest continuous forest. The distances between the closest study sites (edge to edge) ranged from 0.5 to $4 \mathrm{~km}$. The total area of igune woodlots within a study site accounted for $0.9-15 \%$ of the area.

\section{General characteristics of the bird community}

Murata and Takehara (unpublished observation) reported that 34 bird species were observed in the igune agricultural landscapes in Oshu from August 2001 to June 2002. Summer migrants remain in this region from May until September, whereas winter migrants stay from November until March. Many resident species initiate mating behavior in March and subsequently build nests, incubate eggs, and rear their nestling. Most fledglings leave nests in July (Matsuda 2008).

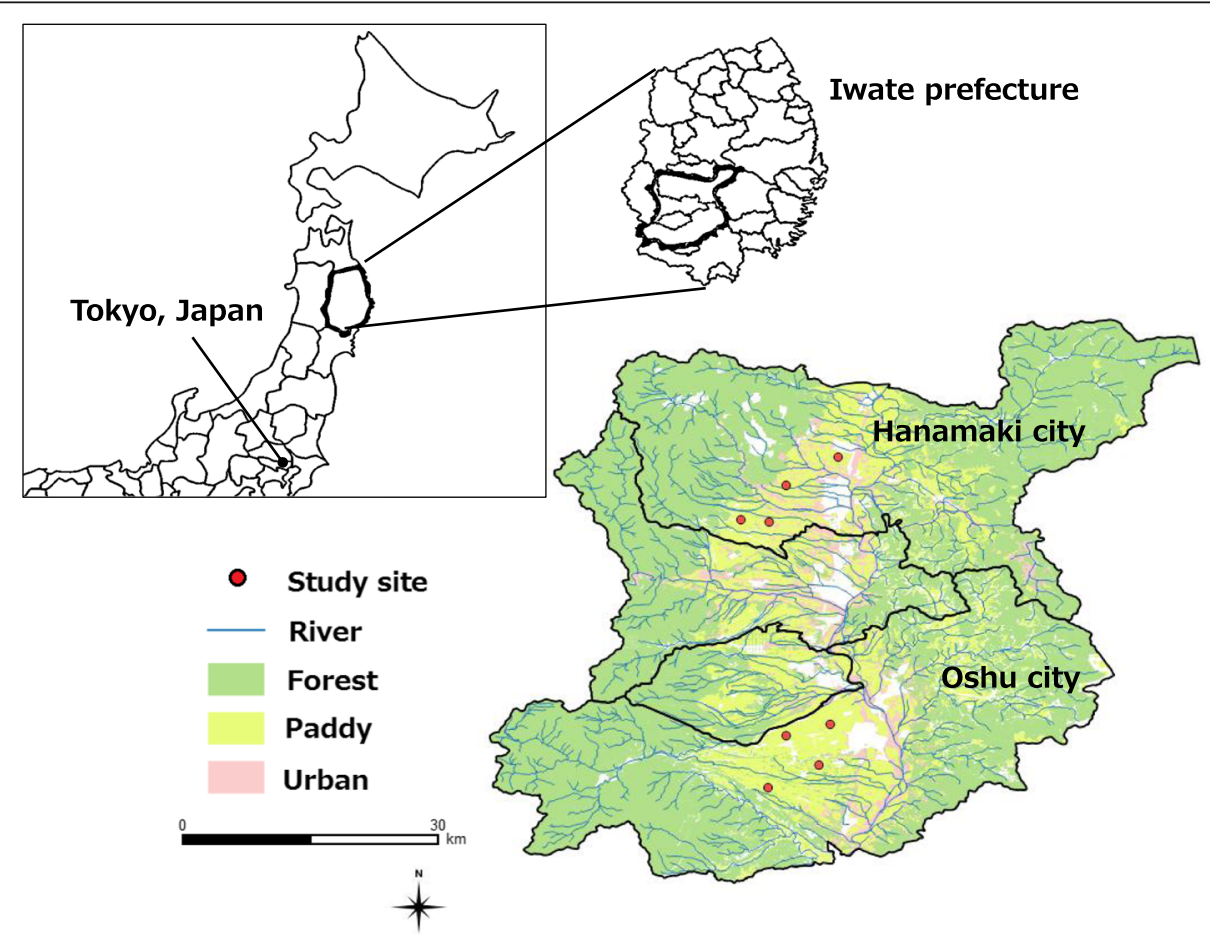

Fig. 2 A map of the study site. The study was conducted at eight sites within igune landscapes in the cities of Oshu and Hanamaki, Iwate Prefecture, Japan 


\section{Bird surveys}

Bird surveys were conducted from 15 August to 22 October 2008, continuing into the middle or late breeding season; i.e., summer migrants had not yet left, and winter migrants had not yet arrived. In this period, many young birds leave the nest and participate in the foraging behavior, so we considered this period to be a good season for observing the birds focusing on guilds of diet and foraging site. Additionally, in the paddy fields, the rice plants reach the maximum height in August and remain at that states until harvesting (about in October), so the foraging environment is considered to be stable during this period.

During the surveys, three censuses at each study site were conducted along a 1-km transect from 05:00 to 10:00; windy or rainy days were avoided. The census transect was slowly walked (1 km in $45 \mathrm{~min}$ ), and the appearance (direct observation of a bird) and voice (identified by listening) of birds were recorded within $50 \mathrm{~m}$ of the census line. Cumulative data (the three censuses for each $1-\mathrm{km}$ transect line) were used for calculating diversity and in subsequent analyses.

\section{Environmental factors}

The number of one igune woodlot at each site (density), the average size (area) of one igune woodlot (mean area), the distance from the nearest continuous forest (distance), the total area of igune woodlots within a site (total area), and the total area of igune woodlots observed directly during bird surveys (in other words, the igune woodlots located within the survey belt for bird census; $100 \mathrm{~m}$ area) were calculated from aerial photographs taken in 2006 using Google Earth and ImageJ software (http://rsb.info. nih.gov/ij/).

The percentage of woodlots in which broadleaf trees covered more than half of the canopy area (broadleaf) and the percentage of woodlots whose shrub layer was cleared (clearing) were also calculated using observational data of igune within a 2-km-long and 500-m-wide belt (including the bird census line) at each study site. These environmental factors and their abbreviations are summarized in Table 1, and the values of the environmental factors at each study site are provided in Appendix 1.

\section{Ecological traits of bird species}

The recorded species were classified into several groups according to their diet, foraging site, and habitat type. Classifications were based on JAVIAN database (Takagawa et al. 2011), descriptions from the literature (Karasawa 1978; Ishida 1987; Clergeau et al. 2001; Watson et al. 2004; Imai and Nakashizuka 2010), two bird books (Takano 1986; Japanese Society for the Preservation of Birds 2002), and an online bird guide (Garizou 1997). Five guild groups were defined in terms of diet: insectivores, granivores, fish eaters,
Table 1 Environmental factors selected in this study

\begin{tabular}{lll}
\hline Factor & Abbreviation & Attribute \\
\hline Number of igune within each site & Density & Numerical \\
$\begin{array}{l}\text { Average area of igune woodlots } \\
\text { within each site }\end{array}$ & Mean area & Numerical \\
$\begin{array}{l}\text { Distance from nearest large forest } \\
\text { habitat to the center of each site }\end{array}$ & Distance & Numerical \\
$\begin{array}{l}\text { Total area of igune woodlots within } \\
\text { each site }\end{array}$ & Total area & Numerical \\
$\begin{array}{l}\text { Total area of igune woodlots observed } \\
\text { directly during bird surveys }\end{array}$ & 100 m area & Numerical \\
$\begin{array}{l}\text { Percentage of igune which included the } \\
\text { broadleaf more than half in canopy area } \\
\begin{array}{l}\text { Percentage of igune which was pruned } \\
\text { bushes }\end{array}\end{array}$ & Broadleaf & Numerical \\
\end{tabular}

omnivores, and carnivores. All species were classified into one of five mutually exclusive diet guilds according to their predominant diet (Table 2). Three guild groups were defined in terms of foraging site: ground, foliage, and others (included species that forage on bark or while flying) (Table 2). Birds were also divided into four groups in terms of habitat type: farmland, forest, both, and water (Table 2). All classifications are summarized in Appendix 2. We only analyzed guilds with five or more species and thus omitted the guilds of fish eaters, carnivore, granivore, and omnivore. In the same way, we omitted the habitat type of water. We also omitted the foraging guild, others, from further analysis.

\section{Diversity indices}

To evaluate avian diversity, we calculated diversity indices using cumulative data from the three censuses along the

Table 2 Classification of avian species into guild group and habitat type based on their ecological trait

\begin{tabular}{|c|c|c|}
\hline Ecological traits & Guild group & Guild or category \\
\hline \multirow[t]{5}{*}{ Diet } & Insectivore & Insectivore \\
\hline & Granivore & Granivore, seed eater \\
\hline & Fish eater & Fish eater \\
\hline & Carnivore & Carnivore, raptor, scavenger \\
\hline & Omnivore & $\begin{array}{l}\text { Omnivore, any species spanning two or } \\
\text { more guilds; for example, frugivore- } \\
\text { insectivore }\end{array}$ \\
\hline \multirow[t]{3}{*}{ Foraging site } & Foliage & Species foraging on branches or foliage \\
\hline & Ground & Species foraging on ground \\
\hline & Others & $\begin{array}{l}\text { Any species spanning two or } \\
\text { more guilds; for example, foraging on } \\
\text { bark or while flying }\end{array}$ \\
\hline \multirow[t]{4}{*}{ Habitat type } & Farmland & Species using farmland (not using forest) \\
\hline & Forest & Species using forest (not using farmland) \\
\hline & Both & Species using both farmland and forest \\
\hline & Water & Species using river, lake, and sea \\
\hline
\end{tabular}


$1-\mathrm{km}$ census line. The diversity indices were the number of species $(S)$, Shannon's diversity index $(H$, based on bird abundance), and equitability $(E)$ for whole communities at each site and then for each guild group. The correlation coefficients among diversity indices of the whole community and guilds were calculated to determine which ecological traits affected the diversity of the whole community. $H$, which accounts for both species richness and evenness, was calculated using the following formula:

$$
H^{\prime}=-\Sigma p_{i} \ln \left(p_{i}\right)
$$

where $p_{i}$ is the importance value (the proportion of species $i$ in abundance out of all species). Equitability $(E)$ is calculated by dividing $H^{\prime}$ by $H^{\prime} \max (=\ln S)$. Values of $H^{\prime}$ and $E$ for ecological guild groups were calculated based on the bird abundance.

\section{Relationships between avian communities and environmental factors}

Canonical correspondence analysis (CCA) was conducted to determine the factors affecting avian community composition (Ter Braak 1986). In order to avoid the multicollinearity problem, we dropped the variables that showed high correlation from analysis and only use four variables (Suzuki and Takenaka 2009). Data on the bird abundance for each species were analyzed using $\mathrm{R}$ software (version 3.3.1; R Core Team 2016).

The relationships between species diversity of the avian community and environmental factors were analyzed using a generalized linear model (GLM) by R software (version 3.3.1; R Core Team 2016). The diversity indices and composition of functional groups or guilds were treated as dependent variables, and environmental factors were treated as explanatory variables. The objective variables followed a Gaussian distribution or Poisson distribution. We ran a GLM with no or one explanatory variable and compared them by Akaike's information criterion (AIC) value to determine the relevant factors. The lowest values of AIC were adopted as the best-fit models.

\section{Results}

\section{Environmental factors}

Several environmental factors were significantly correlated with one another (Table 3), so we adopted only four variables (density, distance, total area, and broadleaf) for CCA. Clearing was negatively correlated with total area $(r=-0.79, P<0.05)$ and the second CCA axis $(A X 2$; $r=-0.71, P<0.05)$. Mean area was positively correlated with broadleaf $(r=0.79, P<0.05)$ and total area $(r=0.77$, $P<0.05$ ), and total area was strongly and negatively correlated with the first CCA axis $(A X 1 ; r=-0.87, P<0.01)$. $100 \mathrm{~m}$ area was strongly and positively correlated with total area $(r=0.92, P<0.01)$ and mean area $(r=0.73$, $P<0.05)$ and negatively correlated with clearing $(r=-0.79$, $P<0.05)$ and the first CCA axis $(A X 1 ; r=-0.73, P<0.05)$.

\section{Recorded birds}

In total, 31 species and 1843 observations were recorded for the birds in all sites (Fig. 3). Only one species, Hirundo rustica, was a migrant species, and all others were residents. Columba livia was the only alien species observed in this study, occurring at two of the eight sites. Totally, four raptor species, Accipiter gentilis, Buteo buteo, Milvus migrans, and Falco peregrinus, were found.

For the diet guilds, over half of all species at a given site were classified as insectivores. In terms of the foraging guilds, more than half of the species were categorized as ground foragers. Regarding the habitat type, more than half of the species were categorized as farmland.

The values of $H^{\prime}$ and $E$ of the whole community ( $H_{\mathrm{W}}$ and $E_{\mathrm{W}}$, respectively) were significantly and positively correlated $(r=0.92, P=<0.01)$, but not with number of species. For the diet guilds, values of $H^{\prime}$ and $E\left(H^{\prime}(\mathrm{d})\right.$ and $E(\mathrm{~d})$, respectively) were positively correlated with $H_{\mathrm{W}}(r=0.89$,

Table 3 Single correlation coefficients ( $r$ ) between environmental factors

\begin{tabular}{|c|c|c|c|c|c|c|c|c|c|}
\hline & Density & Distance & Total area & Broadleaf & Mean area & Clearing & $100 \mathrm{~m}$ area & $A \times 1$ & $A \times 2$ \\
\hline Density & 1 & - & - & - & - & - & - & - & - \\
\hline Distance & -0.05 & 1 & - & - & - & - & - & - & - \\
\hline Total area & 0.35 & 0.56 & 1 & - & - & - & - & - & - \\
\hline Broadleaf & -1.54 & 0.58 & 0.42 & 1 & - & - & - & - & - \\
\hline Mean area & -1.23 & 0.61 & $0.77^{*}$ & $0.79^{*}$ & 1 & - & - & - & - \\
\hline Clearing & -0.16 & -0.4 & $-0.79^{*}$ & -0.34 & -0.52 & 1 & - & - & - \\
\hline $100 \mathrm{~m}$ area & 0.20 & 0.67 & $0.92^{* *}$ & 0.39 & $0.73^{*}$ & $-0.79^{*}$ & 1 & - & - \\
\hline$A X 1$ & -0.53 & -0.64 & $-0.87^{* *}$ & -0.39 & -0.6 & 0.55 & $-0.73^{*}$ & 1 & - \\
\hline$A \times 2$ & -0.4 & 0.01 & 0.41 & 0.33 & 0.45 & $-0.71^{*}$ & 0.50 & 0.05 & 1 \\
\hline
\end{tabular}

${ }^{*} P<0.05 ;{ }^{* * P}<0.01 ;{ }^{* * *} P<0.001$

Note that CCA was conducted using density, distance, total area, and broadleaf. AX1 is the first axis and AX2 is the second axis in CCA 

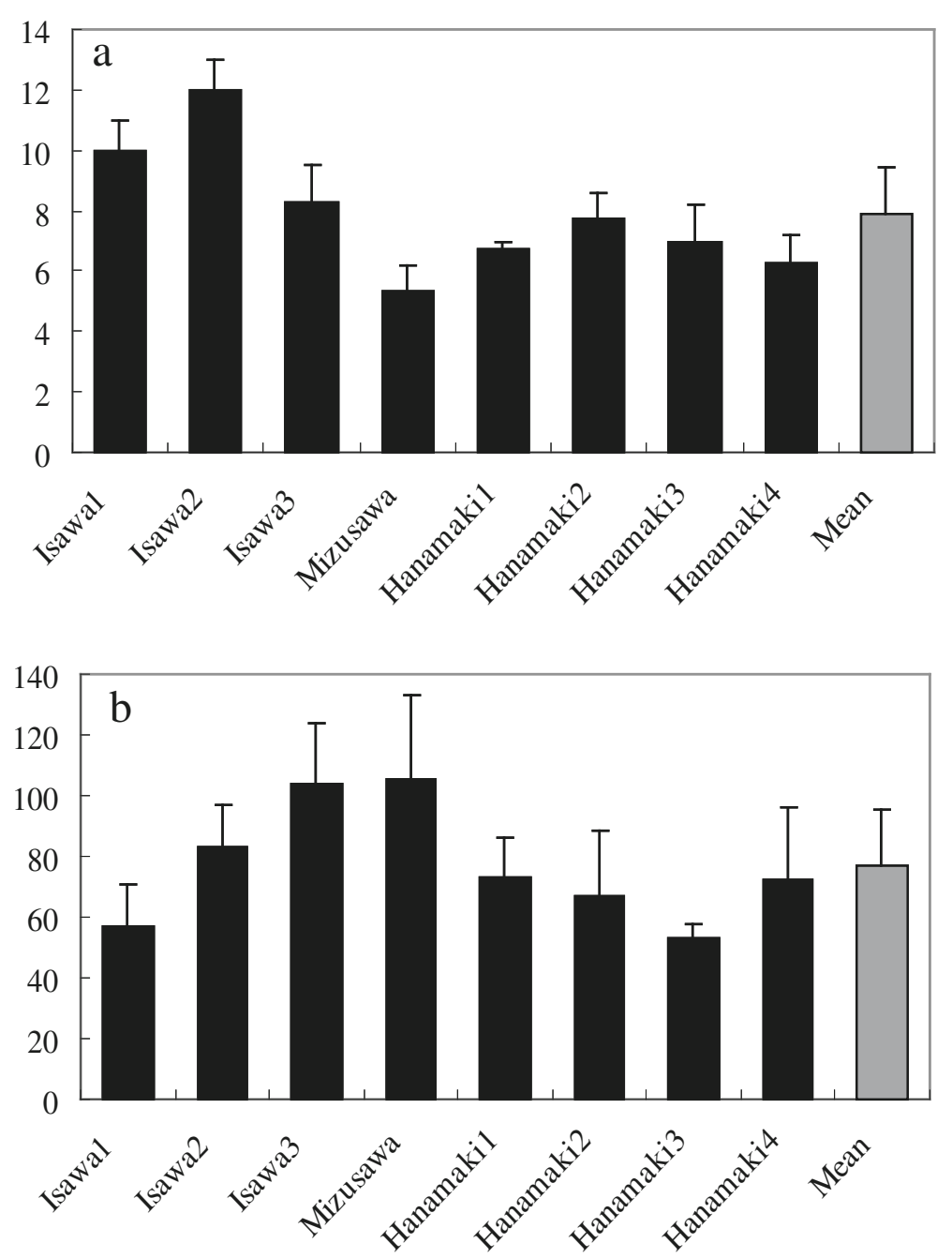

Fig. 3 The average number of species per survey in each site. The results of censuses at each study site obtained from three observation data were averaged. The mean and standard error are shown. a The number of species recorded. $\mathbf{b}$ The bird abundance recorded

$P<0.01)$ and $E_{\mathrm{W}}(r=0.92, P<0.01)$. In the same way, values of $H^{\prime}$ and $E$ for the habitat type $(H(\mathrm{~h})$ and $E(\mathrm{~h})$, respectively) were positively correlated with $H_{\mathrm{W}}(r=0.92$, $P<0.01)$ and $E_{\mathrm{W}}(r=0.93, P<0.001)$ (Table 4$)$.

\section{Relationships between avian communities and environmental factors}

$A X 1$ and $A X 2$ of the CCA explained 36.5 and $26.5 \%$ of the variation in the avian community, respectively. $A X 1$ was strongly negatively correlated with total area $(r=-0.87, P<0.01)$, so it roughly represents the gradient of forested area (or paddy field area) (Fig. 4, Table 3). On the other hand, the interpretation of $A X 2$ was complicated. Although $A X 2$ was positively correlated with total area and negatively correlated with density, the correlation between $A X 2$ and environmental variables (density, distance, total area, and broadleaf) was weak (Fig. 4, Table 3).
Several trends were observed based on the location of species in the CCA plot (Fig. 4). Foliage-foraging species appeared to be concentrated in the upper left area, with low values along $A X 1$ and high values along $A X 2$. Insectivore species were also concentrated in the upper left. Forest habitat species appeared to be concentrated in the left area, with low values along $A X 1$. On the other hand, the species using both forest and farmland appeared to be concentrated in the upper area, with high values along $A X 2$. The raptor species (Accipiter gentilis, Buteo buteo, Milvus migrans, and Falco peregrinus) exhibited high values along $A X 1$.

In the GLM analyses, we compared AIC values between each environmental factor about the diversity indices (Fig. 5). Total area positively affected $H_{\mathrm{W}}^{\prime}(P<0.05)$ and $H^{\prime}$ of the diet guilds $(P<0.05)$. Clearing negatively affected $H_{\mathrm{W}}$ $(P<0.01), H^{\prime}$ of diet guilds $(P<0.05)$, and $E$ of diet guilds $(P<0.05) . A X 2$ positively affected $H_{\mathrm{W}}(P<0.05), E_{\mathrm{W}}(P<$ 0.05), $H^{\prime}$ of diet guilds $(P<0.01)$, and $E$ of diet guilds $(P<0.01)$. 
Table 4 The correlation coefficients ( $r$ ) between indices

\begin{tabular}{|c|c|c|c|c|c|c|c|c|c|}
\hline & \multicolumn{3}{|c|}{ Whole communities } & \multicolumn{2}{|c|}{ Diet guilds } & \multicolumn{2}{|c|}{ Foraging site guilds } & \multicolumn{2}{|c|}{ Habitat type } \\
\hline & $N_{W}$ & $H_{W}^{\prime}$ & $E_{W}$ & $H^{\prime}(\mathrm{d})$ & $E(d)$ & $H^{\prime}(\mathrm{f})$ & $E(\mathrm{f})$ & $H^{\prime}(\mathrm{h})$ & $E(h)$ \\
\hline \multicolumn{10}{|c|}{ Whole communities } \\
\hline$N_{W}$ & & - & - & - & - & - & - & - & - \\
\hline$H_{W}^{\prime}$ & 0.54 & 1 & - & - & - & - & - & - & - \\
\hline$E_{W}$ & 0.18 & $0.92^{* *}$ & 1 & - & - & - & - & - & - \\
\hline \multicolumn{10}{|c|}{ Diet guilds } \\
\hline$H^{\prime}(\mathrm{d})$ & 0.35 & $0.89^{* *}$ & $0.89^{* *}$ & 1 & - & - & - & - & - \\
\hline$E(d)$ & 0.24 & $0.87^{* *}$ & $0.92^{* *}$ & $0.95^{* * *}$ & 1 & - & - & - & - \\
\hline \multicolumn{10}{|c|}{ Foraging site guilds } \\
\hline$H^{\prime}(f)$ & 0.40 & 0.56 & 0.45 & 0.26 & 0.28 & 1 & - & - & - \\
\hline$E(\mathrm{f})$ & 0.40 & 0.60 & 0.49 & 0.30 & 0.31 & $1^{* * *}$ & 1 & - & - \\
\hline \multicolumn{10}{|c|}{ Habitat type } \\
\hline$H^{\prime}(\mathrm{h})$ & 0.34 & $0.92^{* *}$ & $0.92^{* *}$ & $0.76^{*}$ & $0.78^{*}$ & 0.65 & 0.68 & 1 & - \\
\hline$E(\mathrm{~h})$ & 0.26 & $0.90^{* *}$ & $0.93^{* * *}$ & $0.75^{*}$ & $0.79^{*}$ & 0.65 & 0.69 & $0.99^{* * *}$ & 1 \\
\hline
\end{tabular}

${ }^{*} P<0.05 ; * * P<0.01 ; * * P<0.001$

$H^{\prime}(\mathrm{d})$ and $E(\mathrm{~d})$ mean the value of $H^{\prime}$ and $E$ of diet guild, $H^{\prime}(\mathrm{f})$ and $E(\mathrm{f})$ mean the value of $H^{\prime}$ and $E$ of foraging site guild, and $H^{\prime}(\mathrm{h})$ and $E(\mathrm{~h})$ mean the value of $H^{\prime}$ and E of habitat type

Figure 6 showed the comparison of AIC value between each environmental factor about guild groups. Total area positively affected both the species number and the bird abundance of insectivore $(P<0.01$ and $P<0.001$, respectively). On the other hand, clearing negatively affected both the species number and the bird abundance of insectivore $(P<0.01$ and $P<0.001$, respectively).

In terms of foraging site guilds, the bird abundance of foliage-foraging increased in environments with higher values of distance $(P<0.001)$, total area $(P<0.001)$, and broadleaf $(P<0.01)$ but decreased with increasing $A X 1$ $(P<0.001)$. On the other hand, the bird abundance of ground-foraging decreased with increasing $A X 2$, mean area, and total area (all of them $P<0.001$ ) and increased with higher values of clearing $(P<0.001)$.

Regarding the habitat type, forest species showed similar behavior to insectivore. While total area positively affected both the species number and the bird abundance $(P<0.01$ and $P<0.001$, respectively), clearing negatively affected both the species number and the bird abundance $(P<0.01$ and $P<0.001$, respectively). Farmland species, on the other hand, showed similar behavior to ground-foraging species. The bird abundance of the farmland decreased with increasing $A X 2$, mean area, and total area (all of them

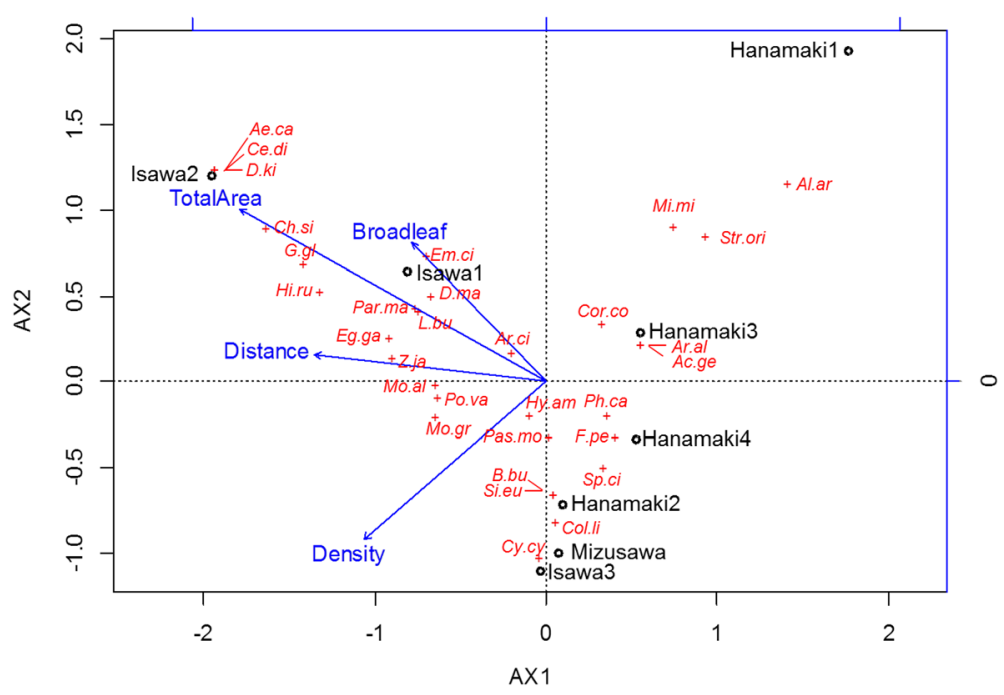

Fig. 4 The result of CCA. The red plus sign indicated the scores of each species and the while circles indicated the scores of each study sites. The abbreviation in Appendix 2 was used for species name 


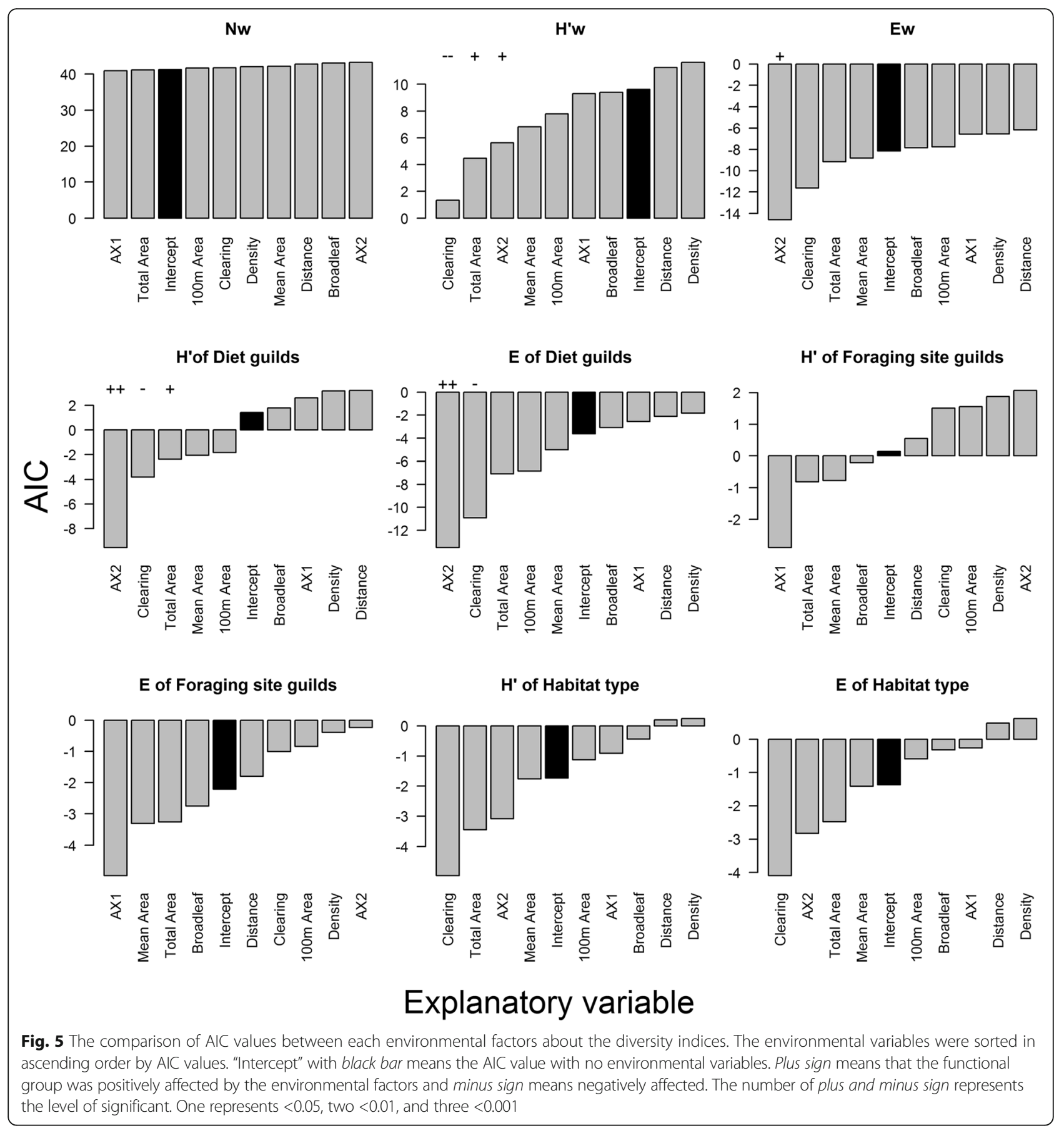

$P<0.001)$ and increased with higher value of clearing, distance, and density (all of them $P<0.001$ ). The species using both forest and farmland showed behavior like neither forest species nor farmland species. This species increased with increasing $A X 2(P<0.001)$ and lower value of density $(P<0.001)$.

As for the species number, ground-foraging species, farmland species, and the species both using forest and farmland did not show the relationship with any environmental factors.

\section{Discussion}

The results of CCA indicated that the total area of woodlots most strongly affected the avian community in this agricultural landscape. However, since we initially dropped clearing which had a strong correlation with total area from environmental variables in CCA, the presence of shrub layer in igune woodlots might also affect the community. The interpretation of second axis in CCA $(A X 2)$ is difficult. Given the relation with total area (positive) and density (negative), $A X 2$ might be interpreted as gradient of human interference. 


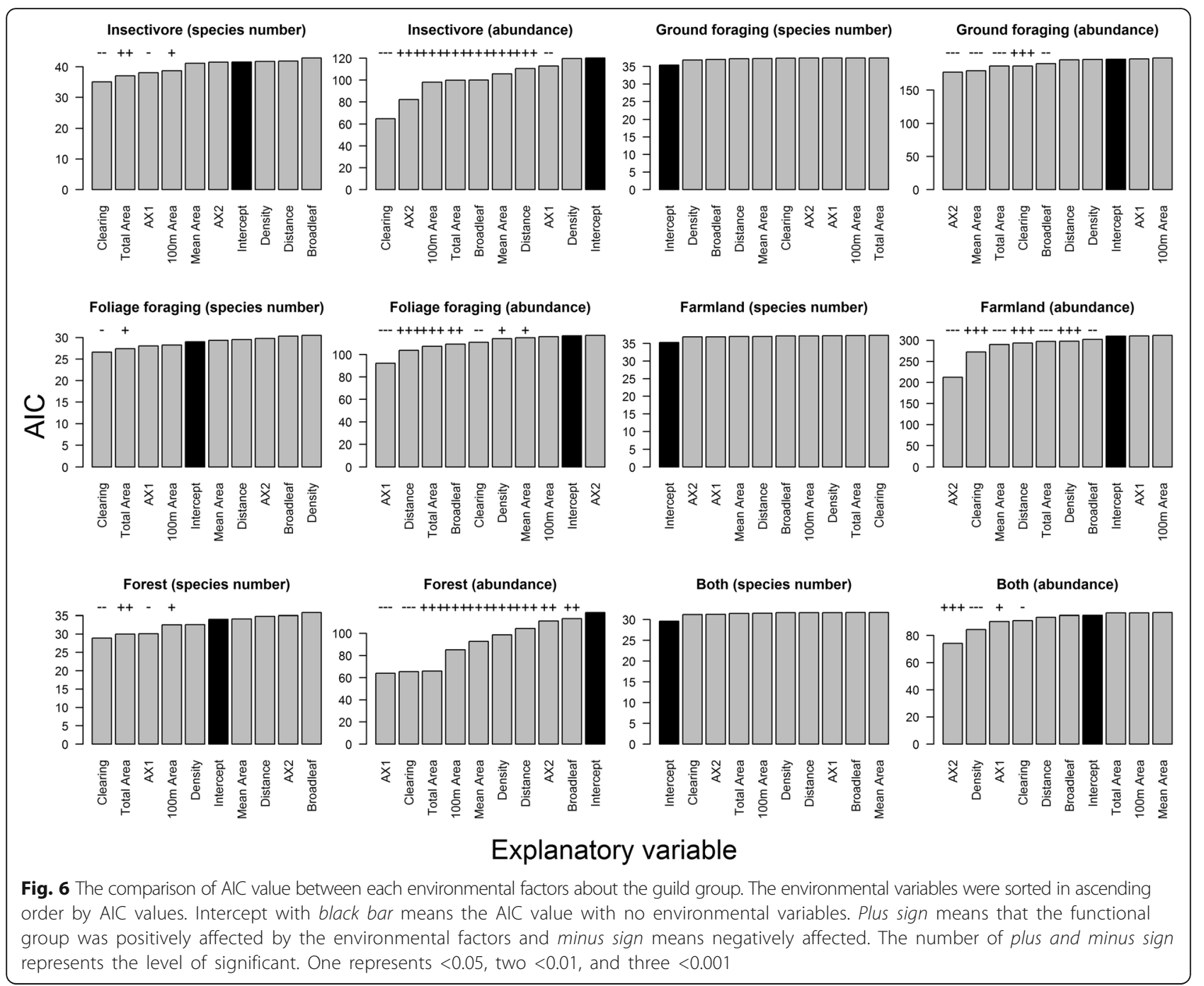

While density means the number of igune woodlots within a site, it also means the number of house or population density since the igune woodlots exists with farmers' houses. The negative correlation with clearing, the effect of mowing by human, also supports this interpretation.

The total area of woodlots, presence of shrub layer in igune, and $A X 2$ were also important in explaining several characteristics of guild structure in the GLM analyses. Total forested area positively affected insectivore species, leading to increases in the $H^{\prime}$ of the whole community and $H^{\prime}$ of diet guilds. Dunn (2000) demonstrated that insect abundance and diversity were higher near isolated trees in crop fields than those in open sites. Our results suggest that large forested areas contain more habitats for insects, thus favoring insectivorous bird species. In our study, forest species also increased in environments with higher values of total forested area. Given that forest habitats have recently been in decline (Iida and Nakashizuka 1995; Hino 2004; Forestry
Agency 2014), igune woodlots are now important in providing alternative habitats for forest species.

The presence of shrubs in igune was also important to avian species richness, likely due to a sheltering effect for small-sized birds from predators, such as raptor species. All species except for ground-foraging and farmland species increased in the presence of a developed bush community in igune, which suggests that igune woodlots function not only as foraging sites but also as resting or shelter sites from predators. In a previous study on forest-boundary crossing, Sieving et al. (2004) reported that shrubs were attractive because they provided escape cover and room to maneuver.

Regarding $A X 2$, which might be interpreted as a human interference effect, less human interference had a positive effect on the abundance of species using both forest and farmland. The mosaic landscape of igune woodlots and paddy field is considered to be favorable environment for the species using forest and farmland. The bird abundance 
of this species showed strong positive correlation with $A X 2$ and preferred the igune landscape which had less interference of human. This suggests that the condition of each landscape component is also important when we consider the landscape complementation and the effect of mosaic structure of landscape.

Although the abundance of farmland and groundforaging species were affected by the environmental factor relevant to igune in GLM analysis, its species number was not affected by any environmental factors relevant to igune. So, we considered that igune type would not lead to a decrease in species number of these species and these species could live in all over this landscape. Murata and Takehara reported in 2004 that species richness was higher in igune than that in secondary forests (unpublished observation) and Hino (2004) described in his book that species richness was reduced in cedar or cypress plantation. From these facts, we can suppose that the small patch forest like igune would not have a negative impact on any species and is more important for enhancement of bird species richness compared to simply large forest.

Several other environmental factors also affected the avian community. For example, broadleaf trees in igune provide foraging sites for foliage-foraging species. In addition, these broadleaf trees may also provide food for frugivorous birds (Miura 1998), although this aspect of igune was not examined in detail for this study. The distance from the nearest continuous forest habitat may also affect bird communities to some extent. The bird abundance of insectivorous and foliage-foraging species increased in environments with high densities of igune as well as in those located far from large forest habitats. In a study of the fragmented landscape of small forest patches, Uezu et al. (2008) observed a higher richness of forest species in small patches. These authors concluded that the detection of forest species in small patches reveals a higher potential of these habitats to facilitate landscape connectivity, although they did not measure species movement itself (Uezu et al. 2008). Fischer and Lindenmayer (2002) also examined the behavior of birds in small patches of paddock trees scattered throughout a grazing landscape. They found that several species, particularly foliage-foraging species, preferred relatively densely distributed paddock trees within the landscape when moving from one tree to another (Fischer and Lindenmayer 2002). In addition, they suggested that when birds were remote from large forest habitats, the importance of paddock trees as stepping stones increased, perhaps because birds attempted to avoid open areas where they were more exposed to predators and/or because food resources in the open were scarce (Fischer and Lindenmayer 2002). In this study, the positive relationship between foliage-foraging species and the distance from nearest continuous forest may support the conclusions of Fischer and Lindenmayer (2002).
Notably, four raptor species were observed in the igune traditional agricultural landscape. Raptors are at the top of the food chain and are considered indicator species of sound ecosystems (Sergio et al. 2006; Kéry et al. 2008). Among these raptor species, $A$. gentilis and $F$. peregrinus have been categorized as a near-threatened species and an endangered species, respectively, by the Ministry of the Environment. F. peregrinus was generally known to appear in sea cliff or other open habitats, but not in continuous large forests, and $A$. gentilis and B. buteo favor the open habitats as hunting fields especially in winter season (Morioka et al. 1995). These facts are consistent with our result that all four raptors had high scores of $A X 1$, which had negative correlation with the total area of woodlots. Given the strong negative correlation between total area and clearing, our study suggests that the raptor species prefer the environments with no shrubs, where an open forest understory likely facilitated the detection of prey.

In addition, igune woodlots are important for raptor species because it also provides perches. Sheffield et al. (2001) showed that supplemental perch and short vegetation increase the hunting performance of the raptor, American kestrels (Falco sparverius). They also suggested that the facilitating predation by raptors may reduce populations of prey species that cause crop damage. This may be applied to our study, suggesting that the traditional land use such as igune may have maintained ecosystem services which prevent the crop damage by small mammals.

In this study, we focused on three ecological traits (diet, foraging site, and habitat type) and discussed the importance of igune woodlots only from these aspects. However, there is also possibility that igune woodlots might function as important nesting site for some species. In order to examine this, the further survey of breeding season (especially from April to July) is required.

Beginning decades ago with the general decline of traditional lifestyles, some igune woodlots have been abandoned or logged (Koganezawa et al. 2002; Hirabuki and Fukuda 2006). The total forested area of igune has decreased in many areas. In addition, some farmers have abandoned management efforts, such as shrub clearing, in igune woodlots. Such changes can have serious impacts on the avian community in igune landscapes, as indicated in this study. Our results clearly suggest that maintaining igune woodlots is a crucial component of enhancing avian diversity within a traditional agricultural landscape in northern Japan.

\section{Conclusions}

Our results suggest that maintaining igune landscapes may enhance avian diversity within this landscape, although the effects of shrubs within igune varied; developed bush communities increased the evenness of the avian community, whereas some raptor species preferred an open forest understory. 


\section{Appendix 1}

Table 5 Environmental factors of each study site

\begin{tabular}{|c|c|c|c|c|c|c|c|}
\hline Study site & Density & Mean area (ha) & Distance $(\mathrm{m})$ & Total area(ha) & Broadleaf (\%) & Clearing (\%) & $100 \mathrm{~m}$ area (ha) \\
\hline Isawa1 & 82 & 0.29 & 2643 & 23.91 & 0.19 & 0.31 & 0.70 \\
\hline Isawa2 & 86 & 0.56 & 6615 & 47.78 & 0.20 & 0.17 & 3.93 \\
\hline Isawa3 & 119 & 0.07 & 1838 & 8.48 & 0.00 & 0.76 & 0.37 \\
\hline Mizusawa & 64 & 0.04 & 4682 & 2.87 & 0.12 & 0.71 & 0.07 \\
\hline Hanamaki1 & 25 & 0.13 & 2039 & 3.36 & 0.08 & 0.44 & 0.64 \\
\hline Hanamaki2 & 104 & 0.11 & 3689 & 11.24 & 0.00 & 0.59 & 0.39 \\
\hline Hanamaki3 & 75 & 0.16 & 1171 & 12.18 & 0.04 & 0.73 & 0.12 \\
\hline Hanamaki4 & 13 & 0.40 & 4150 & 5.22 & 0.23 & 0.85 & 0.04 \\
\hline
\end{tabular}

\section{Appendix 2}

Table 6 The classifications of species into each group. The classifications were based on literatures (see the text)

\begin{tabular}{|c|c|c|c|c|}
\hline Species name & Abbreviation & Diet & Foraging site & Habitat type \\
\hline Phalacrocorax carbo & Ph. ca & Fish eater & Other & Water \\
\hline Ardea alba & Ar. al & Fish eater & Other & Farmland \\
\hline Egretta garzetta & Eg. ga & Fish eater & Other & Farmland \\
\hline Ardea cinerea & Ar. ci & Fish eater & Other & Farmland \\
\hline Milvus migrans & Mi. mi & Carnivore & Ground & Both \\
\hline Accipter gentilis & Ac.ge & Carnivore & Ground & Both \\
\hline Buteo buteo & B. bu & Carnivore & Ground & Farmland \\
\hline Falco peregrinus & F.pe & Carnivore & Ground & Farmland \\
\hline Streptopelia orientalis & Str. ori & Granivore & Ground & Both \\
\hline Dendrocopos major & D. ma & Insectivore & Other & Forest \\
\hline Dendrocopos kizuki & D. ki & Insectivore & Foliage & Forest \\
\hline Alauda arvensis & Al. ar & Insectivore & Ground & Farmland \\
\hline Hirudo rustica & Hi. ru & Insectivore & Other & Farmland \\
\hline Motacilla alba & Mo. al & Insectivore & Ground & Farmland \\
\hline Motacilla grandis & Mo.gr & Insectivore & Ground & Farmland \\
\hline Hypsipetes amaurotis & Hy. am & Insectivore & Foliage & Both \\
\hline Lanius bucephalus & L. bu & Insectivore & Ground & Both \\
\hline Cettia diphone & Ce. di & Insectivore & Foliage & Both \\
\hline Aegithalos caudatus & Ae. Ci & Insectivore & Foliage & Forest \\
\hline Poecile varius & Po. va & Insectivore & Foliage & Forest \\
\hline Parus minor & Par.ma & Insectivore & Foliage & Forest \\
\hline Sitta europaea & Si. eu & Insectivore & Other & Forest \\
\hline Zosteros japonicus & Z. ja & Insectivore & Foliage & Forest \\
\hline Emberiza cioides & Em. ci & Insectivore & Ground & Both \\
\hline Chloris sinica & Ch. si & Granivore & Ground & Farmland \\
\hline Passer montanus & Pas. mo & Omnivore & Ground & Farmland \\
\hline Spodiopsar cineraceus & Sp. ci & Omnivore & Ground & Farmland \\
\hline Garrulus glandarius & G. gl & Insectivore & Ground & Forest \\
\hline Cyanopica cyanus & Cy. cy & Omnivore & Ground & Forest \\
\hline Corvus corone & Cor. co & Omnivore & Ground & Both \\
\hline Columba livis & Col. li & Granivore & Ground & Farmland \\
\hline
\end{tabular}




\section{Acknowledgements}

We would like to thank Drs. S. Satoki and K. Hikosaka (Tohoku University) for their valuable advice. Dr. H. Kurokawa (Forestry and Forest Products Research Institute) gave me kind advice concerning the statistical analysis and support. All the members of the Laboratory of Functional Ecology gave helpful comments on our researches and encouragement through the discussion in all process of our study. We sincerely thank all of them.

\section{Funding}

This research was partly supported by the Environment Research and Technology Development Fund (S-15 Predicting and Assessing Natural Capital and Ecosystem Services (PANCES)) of the Ministry of the Environment, Japan.

\section{Availability of data and materials}

The datasets used during the current study are available from the corresponding author on reasonable request.

\section{Authors' contributions}

$\mathrm{HI}$ and TN designed the study. $\mathrm{HI}$ collected the data and analyzed with $\mathrm{MO}$ HI wrote the initial draft of the manuscript. All authors read and approved the final manuscript.

\section{Competing interests}

The authors declare that they have no competing interests.

\section{Consent for publication}

Not applicable.

\section{Ethics approval and consent to participate}

Not applicable

\section{Author details}

'Graduate School of Life Sciences, Tohoku University Aoba, 6-3, Aramaki, Aoba-ku, Sendai 980-8578, Japan. ${ }^{2}$ Research Institute for Humanity and Nature, 457-4, Kamigamo-Motoyama, Kyoto 603-8047, Japan. ${ }^{3}$ Present Address: Forestry and Forest Products Research Institute, Matsunosato 1, Tsukuba, Ibaraki 305-8687, Japan.

\section{Received: 7 December 2016 Accepted: 16 February 2017}

\section{Published online: 09 March 2017}

\section{References}

Clergeau, P., Jokimäki, J., \& Savard, J. P. L. (2001). Are urban bird communities influenced by the bird diversity of adjacent landscapes? Journal of Applied Ecology, 38, 1122-1134.

Dunn, R. R. (2000). Isolated trees as foci of diversity in active and fallow fields. Biological Conservation, 95, 317-321.

Endo, K., \& Hirano, T. (1990). Breeding records and nesting habitats of the Japanese lesser sparrowhawk accipiter gularis in residential area of Tochigi prefecture Honshu Japan. Japanese Journal Of Ornithology, 39(1), 35-39 (in Japanese).

Fischer, J., \& Lindenmayer, D. B. (2002). The conservation value of paddock trees for birds in a variegated landscape in southern New South Wales. 2. Paddock trees as stepping stones. Biodiversity and Conservation, 11, 833-849.

Forestry Agency (2014) Annual Report on Forest and Forestry in Japan Fiscal Year 2014 (summary). The Forestry Agency Web. http://www.rinya.maff.go.jp/j/ kikaku/hakusyo/26hakusyo/pdf/h26summary.pdf. Accessed 21 Sept 2016.

Fukuoka, K., Hirabuki, Y., \& Araki, Y. (2002). Vegetation of isolated forests in the agro-ecosystem on Isawa Alluvial Fan, Iwate Prefecture. Proceedings Miyagi University Education, 5, 29-38 (in Japanese).

Garizou (1997) Yachoo! online bird guide ver.4.0. (in Japanese)

Gray, M. A., Baldauf, S. L., Mayhew, P. J., \& Hill, J. K. (2007). The response of avian feeding guilds to tropical forest disturbance. Conservation Biology, 21, 133-141.

Hino, T. (2004). The forests of birds. Japan: Tokai University Press (in Japanese).

Hirabuki, Y., \& Fukuda, A. (2006). Farmstead groves and traditional Lifestyle. 1. Development process of two environmental educational programs based on local area field trail results. Proceedings Miyagi University Education, 9, 59-66 (in Japanese)

lida, S., \& Nakashizuka, T. (1995). Forest fragmentation and its effect on species diversity in sub-urban coppice forests in Japan. Forest Ecology and Management, 73(1), 197-210
Imai, H., \& Nakashizuka, T. (2010). Environmental factors affecting the composition and diversity of avian community in mid-to late breeding season in urban parks and green spaces. Landscape Urban Plann, 96, 183-194.

Ishida, K. (1987). The avian community in Lake Yamanaka around the Fuji forest of Tokyo university. Strix, 6, 66-79 (in Japanese).

Japanese Society for the Preservation of Birds. (2002). Bird 630 guide enlarged and (revisedth ed.). Japan: OKU Publishing Service (in Japanese).

Karasawa, K. (1978). Relationship between fruit-eating birds and seed dispersal in urban areas. Japan Journal of Ornithology, 27, 1-20.

Kéry, M., Royle, J. A., \& Schmid, H. (2008). Importance of sampling design and analysis in animal population studies: a comment on Sergio et al. Journal of Applied Ecology, 45, 981-986.

Koganezawa, T, Kitagawa,N, Kato Y (2002) Environmental education and Igune school. Proc Miyagi Univ Educ. 4, 29-36. (in Japanese).

Matsuda, M. (2008). Picture book of wild birds in Japan. Japan: Natsumesha (in Japanese).

Millenium Ecosystem Assessment (2005) Millenium Ecosystem Assassment. http:// www.millenniumassessment.org/en/index.aspx. Accessed 30 Nov 2010.

Ministry of Agriculture, Forestry and Fisheries of Japan (1991) Ministry of Agriculture, Forestry and Fisheries of Japan. http://www.maff.go.jp/e/index. html. Accessed 25 Dec 2009 (in Japanese).

Miura, S. (1998). Homestead woodland developing with climate. Japan: KahokuShinpo-sha (in Japanese).

Morioka, T., Kanouchi, T., Kawada, T., \& Yamagata, N. (1995). The birds of prey in Japan. Japan: Bun-ichi Sogo Press (in Japanese).

Osawa, S., \& Katsuno, T. (2001). The distribution of frogs on paddies locating different landforms in alluvial fan area. Journal of Rural Planning Associatoin, 19(4), 280-288 (in Japanese).

Sandström, U., Angelstam, P., \& Mikusiński, G. (2006). Ecological diversity of birds in relation to the structure of urban green space. Landscape Urban Plann, $77,39-53$.

Savard, J.P. L., Clergeau, P., \& Mennechez, G. (2000). Biodiversity concepts and urban ecosystems. Landscape Urban Plann, 48, 131-142.

Sergio, F., Newton, I., Marchesi, L., \& Pedrini, P. (2006). Ecologically justified charisma: preservation of top predators delivers biodiversity conservation. Journal of Applied Ecology, 43, 1049-1055.

Sheffield, L. M., Crait, J. R., Edge, W. D., \& Wang, G. (2001). Response of American kestrels and gray-tailed voles to vegetation height and supplemental perches. Canadian Journal of Zoology, 79, 380-385.

Sieving, K. E., Contreras, T. A., Maute, K. L., \& Grubb, T., Jr. (2004). Heterospecific facilitation of forest-boundary crossing by mobbing understory birds in north-central Florida. Auk, 121, 738-751.

Simberloff, D. (1998). Flagships, umbrellas, and keystones: is single-species management passé in the landscape era? Biological Conservation, 83, 247-257.

Suzuki, C., \& Takenaka, M. (2009). Application of canonical correspondence analysis to soil microbial ecology. Soil Microorganisms, 63, 32-38 (in Japanese).

Takagawa, S., Ueta, M., Amano, T., Okahisa, Y., Kamioki, M., et al. (2011). JAVIA Database: a species-level database of life history, ecology and morphology of bird species in Japan. Bird Res, 7, R9-R12 (in Japanese).

Takano, S. (1986). Field quide wild birds of Japan. Japan: Wild Bird Society of Japan (in Japanese)

Takeuchi, K. (2003). Satoyama: the traditional rural landscape of Japan. Japan: Springer.

Ter Braak, C. J. (1986). Canonical correspondence analysis: a new eigenvector technique for multivariate direct gradient analysis. Ecology, 67, 1167-1179.

Uezu, A., Beyer, D. D., \& Metzger, J. P. (2008). Can agroforest woodlots work as stepping stones for birds in the Atlantic forest region? Biodiversity and Conservation, 17, 1907-1922.

Watson, J. E., Whittaker, R. J., \& Dawson, T. P. (2004). Habitat structure and proximity to forest edge affect the abundance and distribution of forestdependent birds in tropical coastal forests of southeastern Madagascar. Biological Conservation, 120, 311-327. 